\title{
Comparison of Fungal Biofilm Formation on Three Contemporary Denture Base Materials
}

\author{
${ }^{1}$ Vinay Jain, ${ }^{2}$ Jegdish Babu, ${ }^{3}$ Swati Ahuja, ${ }^{4}$ Russell Wicks, ${ }^{5}$ Franklin Garcia-Godoy
}

\begin{abstract}
Statement of problem: Modern polyamide 'flexible' denture base materials have increased in popularity for use in removable partial dentures in the last several years. The introduction of these newer products warrants investigation of their relative potential to develop fungal biofilms.
\end{abstract}

Purpose: The purpose of this study was to investigate the potential of three denture base materials to support fungal biofilm formation.

Materials and methods: Specimens of two 'flexible' nylon type materials and one traditional heat processed, methyl methacrylate resin material were studied (both polished and unpolished surfaces). The specimens were coated with saliva and evaluated for fungal (Candida albicans) biofilm formation. The fungal biofilm mass formed on denture substrates were evaluated by dry weight analysis and by determining the number of viable fungal cells in the biofilm by MTT viability assay. Alteration in fungal metabolic function following the treatment of the biofilm $C$. albicans with nystatin and fluconazole was determined by XTT assay.

Results: In general, the unpolished surfaces of the denture disks favored the fungal biofilm, the most being on polyamide specimen, Valplast. Significantly, less biofilm was formed on Duraflex and Lucitone surfaces. Biofim on C. albicans was also found to be resistant to antifungal agents. As compared to freshly incubated (grown) planktonic cells, biofilm fungal cells required significantly higher concentrations of nystatin and fluconazole in order to obtain $50 \%$ reduction in metabolic activity.

Conclusion: This study demonstrated the differences in denture materials to support fungal biofilm formation, and also difference between polished and unpolished denture material surfaces. The results demonstrated that one of the polyamide materials (duraflex) had lesser potential to biofilm formation than the others.

\footnotetext{
${ }^{1}$ Associate Professor, ${ }^{2}$ Professor, ${ }^{3}$ Adjunct Assistant Professor ${ }^{4}$ Professor, ${ }^{5}$ Professor and Senior Executive Associate Dean and Chair

1,3,4 Department of Prosthodontics, University of Tennessee Tennessee, United States

${ }^{2,5}$ Department of Bioscience Research, University of Tennessee, Tennessee, United States
}

Corresponding Author: Swati Ahuja, Adjunct Assistant Professor, Department of Prosthodontics, University of Tennessee, Tennessee, United States, Phone: 9014486101 e-mail: sahuja@uthsc.edu
Clinical significance: Unfavorable tissue responses can ensue from the presence of fungal biofilms on dental prosthetics. Resistance to biofilm formation is a factor for dental materials in their selection and usage. This study helps to quantify, evaluate and compare biofilm formation on polished and unpolished surfaces of three commonly used denture base materials. The results of this study helped to identify materials, which may, therefore, be better indicated in clinical applications. Evaluations for the newer denture base materials, specific to these testing methods, appear to be novel in the scientific literature.

Keywords: Biofilm, Candida, Denture base, Fungi, Polyamides.

How to cite this article: Jain V, Babu J, Ahuja S, Wicks R, Garcia-Godoy F. Comparison of Fungal Biofilm Formation on Three Contemporary Denture Base Materials. Int J Experiment Dent Sci 2015;4(2):104-108.

\section{Source of support: Nil}

\section{Conflict of interest: None}

\section{INTRODUCTION}

Polymethylmethacrylate (PMMA), an acrylic resin polymer developed in the 1930s has become the most versatile denture base material in contemporary removable prosthodontics due to its high esthetic quality and substantial mechanical and physical properties to withstand the complex oral environment. ${ }^{1}$ Apart from their numerous advantages acrylic denture base resins have several disadvantages, such as dimensional inaccuracy, brittleness and allergy to methyl methacrylate monomers. ${ }^{2}$

Microbial colonization and formation of biofilms on acrylic denture base resin materials in the oral environment leads to denture stomatitis. ${ }^{3-5}$ Although there is evidence that several specific pathogens are elemental in denture plaque formation, the classic opportunist organism, Candida albicans, is most often associated with denture stomatitis in vivo. ${ }^{6-8}$ Presence and colonization of Candida species, composition and characteristics of denture base materials, fit of the dentures and oral hygiene are factors that determine the onset and severity of Candida associated denture stomatitis. ${ }^{9}$ Multiple epidemiologic studies have suggested the prevalence of denture related stomatitis to be from 10 to $75 \%$ in various experimental populations, with the highest rates seen in elderly and institutionalized patients due to poor oral hygiene and prolonged wear..$^{10-12}$ 
The first stage of colonization within a biofilm involves firm adherence of microorganisms to the surfaces of the oral cavity. ${ }^{13}$ Rather than adhering directly to the prosthesis, the microorganisms are integrated into a salivary pellicle which forms a plaque complex on the denture material. The adherence of these plaques has been influenced by the surface-free energy and surface roughness. ${ }^{14}$ Rough surfaces promote development of plaque due to an increase in surface area and greater difficulty in debridement. ${ }^{15}$ Finally, C. albicans is present in higher numbers on the surface of denture bases as opposed to denture bearing mucosa due to the abiotic nature of the surface of the denture. ${ }^{16-18}$

Recently, polyamide materials have been widely promoted for use as denture bases. Industry estimates suggest that $35 \%$ or more of all current removable partial dentures in North America are being constructed using polyamide materials. The advantages of these materials include: biological inertness, flexibility, elimination of a metallic framework and patient comfort. Little has been published regarding these denture base polymers in the scientific literature, despite their widespread use. A study performed by Fernandez et al concluded that the polyamide material promoted more biofilm growth as compared to the PMMA, however, only one polyamide material (Flexite) was studied. ${ }^{9}$ Currently, new generations of polyamide materials boast improvements in esthetics, polishabilty and toughness. Recently, these materials have been extensively used in geriatric and disabled patients. Majority of these patients are not able to maintain proper oral hygiene and are prone to stomatitis due to changes in mental health, physical disabilities and deterioration of general health. Hence, it is important to assess the biofilm forming potential of the newer polyamide materials.

The objective of this study was to determine the potential differences between three denture base (two polyamide and one PMMA) resins to facilitate fungal biofilm formation. The further objective was to compare the relative smoothness of denture materials to support the biofilm formation. The null hypothesis of this study was that there is no statistically distinguishable $(p>0.05)$ difference in the potential for biofilm formation among the three-denture base materials and their polished and unpolished surfaces.

\section{MATERIALS AND METHODS}

\section{Growth of Fungal Cells}

Candida albicans $(44,505)$ was obtained from ATCC (Manassas, VA). The fungi was grown in Sabouraddextrose broth (SDB; Difco Laboratories, Detroit, MI) in an orbital shaking water bath at $30^{\circ} \mathrm{C}$ for 24 hours. Cells were harvested by centrifugation at $4^{\circ} \mathrm{C}$ and washed twice with phosphate-buffered saline (PBS; $\mathrm{pH}$ 7.2). Suspension of $C$. albicans was adjusted to a concentration of $1 \times 10^{7}$ colony-forming units (CFU) per milliliter, and used in experiments as a standard cell suspension. The cells were examined microscopically to verify non-budding yeast phase, which if found was diskarded.

\section{Preparation of Denture Base Material Disks}

Denture materials tested in the study included, Lucitone 199 (Dentsply), PMMA acrylic resin, Valplast ${ }^{\circledR}$, thermoformed nylon 6 polyamide, and Duraflex ${ }^{\mathrm{TM}}$ (Myerson), thermoformed nylon 12 composite polyamide. 18 disks ( $8 \mathrm{~mm}$ diameter $\times 2 \mathrm{~mm}$ thick) from each denture material were prepared according to the manufacturer's instructions. The surfaces of half of the specimens of each denture material (both the flat surfaces and the edges) were finished and polished as a cameo prosthetic surface with pumice and Acriluster (Buffalo Dental Manufacturing Co), rinsed with double de-ionized water and air dried. The other half of the specimens for consistency of the denture materials were left unpolished to represent an intaglio prosthetic surface. The specimens for consistency were obtained from the manufacturer within 24 hours of their preparation and tested within 4 days. All disks were sterilized with ethylene oxide gas and rinsed thoroughly with sterile deionized water prior to their use in the study. Experiments were performed with triplicate disk specimens for consistency, and each experiment was repeated at least three times.

\section{Preparation of Fungal Biofilms on Denture Material Disks}

Denture base material disks were coated with pooled clarified human saliva by incubating for 2 hours at $37^{\circ} \mathrm{C}$. The disks were rinsed with sterile phosphate buffered saline (PBS; pH 7.4) to remove the unbound salivary components. Each disk was then incubated with $1.0 \mathrm{ml}$ of standard fungal suspension $\left(1 \times 10^{7}\right.$ cells $)$ at $37^{\circ} \mathrm{C}$ for 7 days in a 24-well culture dish. Every 24 hours an aliquot of fresh SAB broth supplemented with $50 \mathrm{mM}$ glucose was added during the entire period of biofilm growth. At the end of incubation period, each disk was rinsed with PBS to remove the unbound fungal cells and then transferred to a fresh culture dish. The number of viable fungal cells was determined by MTT assay (see below).

\section{Determination of Viable Fungal Cells by MTT Assay}

Viable fungal cells on the denture disks were determined by MTT viable assay, using the kit obtained from Roche 
Labs (Indianapolis, IN). After removing the unbound fungal cells, each disk was placed in a 24-well plate, to which $0.5 \mathrm{ml}$ of fresh SAB media was added along with $50 \mu \mathrm{l}$ MTT label and incubated for 4 hours. The plates were incubated overnight after the addition of $0.5 \mathrm{ml}$ solubilizing agent supplied by the manufacturer. An aliquot (200 $\mu \mathrm{l}$ ) from each disk was placed in a flat-bottom 96-well micro titer plate and the absorbance of converted dye was measured at a wavelength of $570 \mathrm{~nm}$ with background subtraction at $690 \mathrm{~nm}$. The actual number of fungal cells colonized on each denture disk was calculated from an optical density standard curve prepared with known number of cells.

\section{Metabolic Activity of Biofilm and Planktonic Fungal Cells}

The metabolic function of both biofilm and planktonic C. albicans was performed by XTT assay. ${ }^{19}$ This mitochondrial function assay was assessed using a previously described 2,3-bis (2-methoxy-4-nitro-5-sulfophenyl)5-\{(phenylamino) carbonyl\}-2H-tetrazolium hydroxide (XTT) assay. ${ }^{13}$ In this assay, the tetrazolium salt XTT is cleaved to an orange-colored formazan product by mitochondrial dehydrogenase by viable cells. Biofilmgrown or freshly cultured fungal cells $\left(1 \times 10^{7}\right.$ cells $)$ were incubated with $50 \mu \mathrm{l}$ of XTT reagent (Roche Labs, Indianapolis, IN) and incubated for 4 hours. The absorbance was measured at a wavelength of $490 \mathrm{~nm}$ with background subtraction at $690 \mathrm{~nm}$ by an ELISA reader.

\section{Dry Weight Analysis of the Fungal Biofilm}

The weight of each denture disk was recorded prior to incubation. The disks were sterilized and used for growing biofilm. The assay was performed with triplicate disks, and repeated three times.

\section{Antifungal Susceptibility Assay}

Freshly cultured and biofilm cells grown on denture disks were collected and suspended to contain $1 \times 10^{7}$ cells $/ \mathrm{ml}$. Nystatin and flucanazole were serially diluted from stock solutions $(5 \mathrm{mg} / \mathrm{ml})$ and each dilution in triplicate was added to the cells and incubated for 24 hours. Following the incubation, cells were collected and the metabolic activity was assessed by the XTT method. ${ }^{19}$

\section{DATA ANALYSIS}

The results were evaluated for statistical significance by analysis of variance (ANOVA) followed by Scheffe's f-test. Difference in results with a p-value less than 0.05 was considered significant.

\section{RESULTS}

Differences in biofilm formation on denture materials:

The results (Graph 1) show that the number of viable C. albicans in biofilm formed on polished disks was significantly lower $(p<0.00176)$ when compared to the unpolished disks of all three materials tested. Among the polished disks, highest number of fungal cells were found on the Valplast (18,680 \pm 1080$)$, followed by Lucitone (12,950 \pm 1070 ). The Duraflex polished disks had least number (6130 \pm 690 ) of viable fungi in the biofilm. The data suggested that the C. albicans prefered rougher surface compared to the polished counterparts of the denture disks.

\section{Dry Weight Analysis}

Dry weight analysis (Table 1) of the biofilm formed on three denture disks appeared to agree with the biofilm data. Unpolished denture disks had more density of fungal biofilm compared to the polished ones $(\mathrm{p}<0.026)$. Highest amount of biofilm was found on unpolished Valplast denture disk, while the least on polished

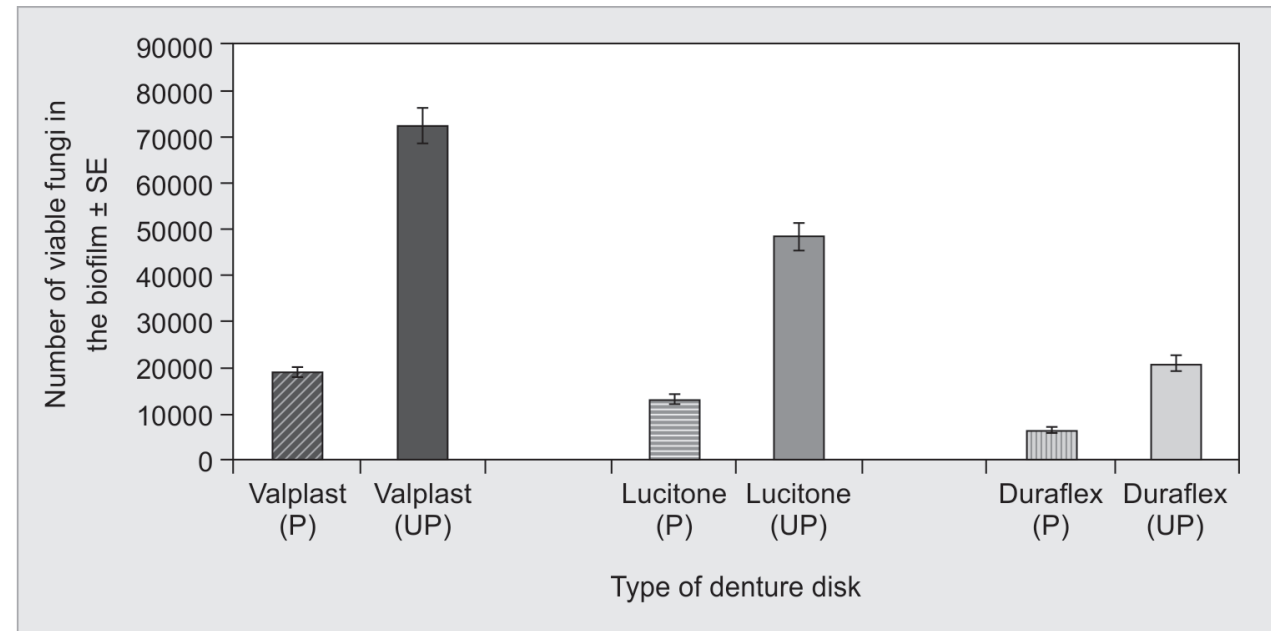

Graph 1: Depicting the number of viable cells on the polished and unpolished surfaces of the three denture base materials 
Table 1: Dry weight analysis of biofilm formed on denture disks

\begin{tabular}{ll}
\hline Denture material & Biofilm dry weight $(m g \pm S E)$ \\
\hline Valplast (P) & $106 \pm 14$ \\
Valplast (UP) & $192 \pm 28$ \\
Lucitone (P) & $68 \pm 12$ \\
Lucitone (UP) & $156 \pm 18$ \\
Duraflex (P) & $22 \pm 6$ \\
Duraflex (UP) & $63 \pm 22$ \\
\hline
\end{tabular}

P: Polished; UP: Unpolished

Duraflex disks. The results strongly suggested that type and surface smoothness affected the formation of fungal biofilms.

Susceptibility of $C$. albicans obtained from biofilm formed on Valplast denture disks to nystatin and fluconazole.

After growing the biofilm on denture disks, the susceptibility of biofilm and planktonic C. albicans to serially diluted antifungal agents, nystatin and fluconazole was compared. The metabolic function of both fungal cells was determined by XTT assay following the incubation with the two antifungal agents. Biofilm grown C. albicans exhibited resistance to both antifungal agents. A $50 \%$ reduction in XTT metabolic activity of biofilm grown cells required $32 \mu \mathrm{g} / \mathrm{ml}$ of nystatin, and $128 \mu \mathrm{g} / \mathrm{ml}$ of fluconazole, while the planktonically grown cells required only $1.0 \mu \mathrm{g} / \mathrm{ml}$ of nystatin and $1.5 \mu \mathrm{g} / \mathrm{ml}$ of fluconazole, respectively.

\section{DISCUSSION}

The null hypothesis in this study was rejected since there was a difference in the potential for biofilm formation among the three-denture base materials. There was also a difference in the potential for biofilm formation among the polished and unpolished surfaces. Similar to Lucitone, valplast and duraflex provided a suitable substratum for colonization of the fungi. The results of the MTT assay demonstrated that unpolished valplast had the highest adherence potential to C. albicans and polished duraflex had the least adherence potential to $C$. albicans. These results corroborate with the results of Fernandez et al who also found that one of the polyamides had higher potential to biofilm formation than PMMA. ${ }^{9}$ Differences in the resin surface charge may have caused differences in adherence potential of the three denture base materials.

The results of the MTT assay also concluded that polished surfaces have a lesser potential for microbial adherence. ${ }^{5,20}$ Rough surfaces produces increased adherence of microorganisms due to greater micro surface area available for attachment. In addition denture surface with cracks, porosities, scratches provide a protective environment for the fungi since it is harder to get the fungus out from them. All the disks with rough surface showed higher potential to fungal biofilm formation than their polished counterparts. ${ }^{5,20}$

In addition to dentures there are several implantable devices in which Candida biofilms develop including catheters, endotracheal tubes, intra cardiac devices, breast implants, prosthetic joints and neurosurgical shunts. The formation of Candida biofilms ultimately results in failure of the implantable device. ${ }^{21}$ In the oral cavity, in addition to successful colonization of $C$. albicans on the surface of denture base, saliva and serum pellicles have a major role in subsequent biofilm formation. ${ }^{22}$ Saliva and serum perform several functions including: clearance modulation, aggregation, nutrition, protection and adhesion of fungal organisms. ${ }^{22}$ However, there is limited flow of saliva under the intaglio surface of the denture (especially maxillary denture). This acts as a contributing factor for biofilm formation since mechanical removal of microorganisms by the flushing action of saliva is lacking.

Cleaning the dentures appropriately helps control the formation of biofilm and denture stomatitis. Older and disabled denture wearers usually have a tendency to wear dentures for prolonged periods of time. Most of these patients cannot maintain proper oral hygiene. Both the patients and their care takers should be educated regarding the adherence potential of the denture base materials and must be taught to maintain proper oral hygiene using a combination of mechanical and chemical cleansing with immersion in denture cleansers for reducing microbial biofilm formation. In addition, these patients should be monitored regularly and put on a strict maintenance recall.

The results of this study should be interpreted with care, since the in vitro nature of the present study does not fully match the complexities of the oral cavity. However, these results provide important data on adherence potential of newer polyamide materials. Further studies are needed to corroborate the findings of the present study. The prescription and manipulation of specific denture base materials may be influenced by these findings, and may benefit the denture wearing population in reducing denture associated stomatitis.

\section{CONCLUSION}

- Polished duraflex had lowest potential to biofilm formation.

- Rough surfaces have a higher potential to biofilm formation than smooth surfaces.

\section{REFERENCES}

1. Phoenix RD. Denture base materials. Dent Clin North Am 1996;40(1):113-120.

2. Kohli S, Bhatia S. Polyamides in dentistry. Int J Scientific Study 2013;1(1):20-25. 
3. Cahn LR. Denture related candidiasis. Oral Surg Oral Med Oral Pathol 1976;41(1):59-60.

4. Cawson RA. Denture sore mouth, the role of Candida. Dent Practit 1965;16(4):138-142.

5. Radford DR, Challacombe SJ, Walter JD. Denture plaque and adherence of Candida albicans to denture-base materials in vivo and in vitro. Crit Rev Oral Biol Med 1999;10(1):99-116.

6. Barbeau J,Seguin J, GouletJP, de Koninck L, AvonSL, Lalonde B, et al. Reassessing the presence of Candida albicans in denture-related stomatitis. Oral Surg Oral Med Oral Pathol Oral Radiol Endod 2003;95(1):51-59.

7. ten Cate JM, Klis FM, Pereira-Cenci T, Crielaard W, de Groot PW. Molecular and cellular mechanisms that lead to Candida biofilm formation. J Dent Res 2009;88(2):105-115.

8. Pires FR, Santos EB, Bonan PR, De Almeida OP, Lopes MA. Denture stomatitis and salivary Candida in Brazilian edentulous patients. J Oral Rehabil 2002;29(11):1115-1119.

9. de Freitas Fernandes FS, Pereira-Cenci T, da Silva WJ, Filho AP, Straioto FG, Del Bel Cury AA. Efficacy of denture cleansers on Candida spp. biofilm formed on polyamide and polymethyl methacrylate resins. J Prosthet Dent 2011;105(1):51-58.

10. Jorge J Jr, Almeida OP, Bozzo L, Scully C, Graner E. Oral mucosal health and disease in institutionalized elderly in Brazil. Community Dent Oral Epidemiol 1991;19(3):173-175.

11. Harding SD, Wilson M, Dickinson C, Howlett J, Hobkirk J. The cultivable microflora of denture plaque from patients with denture-induced stomatitis. Microb Ecol Health Dis 1991;4(3):149-157.

12. Gendreau L, Loewy ZG. Epidemiology and etiology of denture stomatitis. J Prosthodont 2011;20(4):251-260.
13. Douglas LJ. Adhesion of pathogenic Candida species to host surfaces. Microbiol Sci 1985;2(8):243-247.

14. Quireynen M, Marechal M, Steenberghe VD. The influence of surface free energy and surface roughness on early plaque formation: an in vitro study in man. J Clin Periodontol 1990; 17(3):138-144

15. Busscher HJ, Cowan MM, van der Mei HC. On the relative importance of specific and non-specific approaches to oral microbial adhesion. FEMS Microbiol Rev 1992;8(3-4): 199-209.

16. Williams DW, Kuriyama T, Silva S, Malic S, Lewis MAO. Candida biofilms and oral candidosis: treatment and prevention. Periodontol 2000;55(1):250-265.

17. Davenport JC. The oral distribution of Candida in denture stomatitis. Br Dent J 1970;129(4):151-156.

18. Olsen I. Denture stomatitis. Occurrence and distribution of fungi. Acta Odontol Scand 1974;32(5):329-333.

19. Babu JP, Shiloah CBJ, Ofek I. Inhibition of Streptococcus gordonii metabolic activity in biofilm by cranberry juice high molecular weight component. J Biomed Biotechnol 2012;2012:590384.

20. Verran J, Taylor RL, Lees GC. Bacterial adhesion to inert thermoplastic surfaces. J Mater Sci Mater Med 1996;7(10):597-601.

21. Ramage G, Martínez JP, López-Ribot JL. Candida biofilms on implanted biomaterials: a clinically significant problem. FEMS Yeast Res 2006;6(7):979-986.

22. Nikawa H, Hamada T, Yamamoto T, Kumagai H. Effects of salivary or serum pellicles on the Candida albicans growth and biofilm formation on soft lining materials in vitro. J Oral Rehabil 1997;24(8):594-604. 